\title{
Sistemas de liberação de fármaco intrabolsa periodontal
}

\author{
Marcos Luciano Bruschi', Heitor Panzeri², Osvaldo de Freitas' ${ }^{1}$ Elza Helena Guimarães Lara', \\ Maria Palmira Daflon Gremião ${ }^{3^{*}}$ \\ 'Departamento de Ciências Farmacêuticas, Faculdade de Ciências Farmacêuticas de Ribeirão Preto, Universidade de \\ São Paulo, ${ }^{2}$ Departamento de Materiais Dentários e Prótese, Faculdade de Odontologia de Ribeirão Preto, \\ Universidade de São Paulo, ${ }^{3}$ Departamento de Fármacos e Medicamentos, Faculdade de Ciências Farmacêuticas, \\ Universidade Estadual Paulista
}

*Correspondência:

M. P. D. Gremião

Departamento de Fármacos e

Medicamentos

Faculdade de Ciências Farmacêuticas

Universidade Estadual Paulista - UNESP

Rod. Araraquara-Jaú, km 1

14801-902 - Araraquara, SP - Brasil

E-mail: pgremiao@fcfar.unesp.br
A doença periodontal é morbidade com alta prevalência na população mundial. É causada pelo acúmulo de componentes microbianos do biofilme dental no interior das áreas subgengivais do periodonto, desencadeando processo inflamatório que afeta as estruturas de suporte dental, resultando em formação de bolsa periodontal e perda dos dentes, se não tratada. O tratamento convencional consiste de raspagem e alisamento radicular, associado ou não ao uso de antimicrobianos de ação sistêmica, o que implica altas doses, porém com eficácia reduzida, efeitos adversos e dificuldades de adesão ao tratamento por parte do paciente. Nas últimas décadas, o tratamento tem sido otimizado pelo uso de sistemas de liberação de fármaco intrabolsa periodontal, com a vantagem de liberar o fármaco no local de ação, possibilitando prolongar elou controlar sua concentração. A presente revisão aborda os principais sistemas de liberação de fármaco intrabolsa periodontal, o potencial de utilização, assim como os protocolos disponiveis para a avaliação da efetividade dos mesmos na terapia periodontal.

\author{
Unitermos \\ - Doença periodontal \\ - Bolsa periodontal \\ - Sistemas de liberação \\ - Liberação intrabolsa \\ periodontal
}

\section{INTRODUÇÃO}

Entre os vários sistemas do organismo humano, o digestório possui a importante função de mastigação, ingestão e absorção dos alimentos, e eliminação de parte dos resíduos (Erhart, 1987). Os dentes são órgãos acessórios do sistema digestório, estão implantados nos arcos alveolares da maxila e mandíbula e têm por função essencial a mastigação, cortando, moendo e misturando os alimentos ingeridos (Guyton, 1989).

A saúde bucal é muito importante para a manutenção da saúde global do organismo humano. No entanto, vários problemas, tais como neoplasias, disfunções glandulares, cáries e doença periodontal, acometem a cavidade oral. O termo "doença periodontal" define várias doenças associadas com o periodonto (Steinberg, Friedman, 1988). Trata-se de uma morbidade que afeta as estruturas de suporte dos dentes, nomeadamente o ligamento periodontal, cemento, osso alveolar e gengiva (Seymour, Heasman, 1992). Afeta virtualmente a maioria da população mundial, sendo a maior fonte de perda de dente após os 25 anos de idade (Deasy et al., 1989).

Existe evidência esmagadora de que a doença periodontal é causada por acúmulo de componentes 
microbianos do biofilme dental que se acumula no interior das áreas subgengivais do periodonto (Friedman, Golomb, 1982; Listgarten, 1986; Jones et al., 1996; Monbelli, 2003). O epitélio juncional dental é um tecido que não possui a barreira de permeabilidade superficial, constituindo uma via pela qual toxinas, antígenos e enzimas derivados de biofilme bacteriano, que se formam na superfície dental, podem penetrar e atingir o tecido conjuntivo subepitelial. Isto inicia um ciclo inflamatório e de injúrias teciduais, que facilitam a entrada de irritantes pelo sulco dental e exacerbam os danos (Seymour, Heasman, 1992). Eventualmente a destruição tecidual envolverá as estruturas suportes dos dentes e acarretará a perda dental (Medlicott et al., 1994).

A doença periodontal pode ser classificada de acordo com o grau e a extensão do tecido envolvido. $\mathrm{Na}$ gengivite, estágio moderado da doença, a resposta inflamatória é restrita aos tecidos gengivais, sendo caracterizada por intumescimento, vermelhidão e sangramento da gengiva marginal (Steinberg, Friedman, 1988; Medlicott et al., 1994). No caso de periodontite, um estágio mais grave da doença periodontal (Listgarten, 1986), as alterações podem se estender a tecidos mais profundos, sendo que o número de bactérias Gram-negativas pode aumentar para $70 \%$ do total da flora (Steinberg, Friedman, 1988), na maioria anaeróbias restritas ou facultativas (Tanner et al., 1979; Slots, 1979, 1982; Saglie et al., 1982; Loesche et al., 1985; Kaplan et al., 1989; Seymour, Heasman, 1992; Bolstad et al., 1996; Jorgensen, Slots, 2000). Como resultado, pode ocorrer rompimento do ligamento do tecido conectivo á superfície da raiz do dente e migração apical do epitélio juncional, que podem resultar na recessão gengival e formação de bolsa, na exposição do cemento, na perda de osso alveolar e no aumento na mobilidade do dente (Seymour, Heasman, 1992).

A bolsa periodontal é um sulco aprofundado patologicamente (Steinberg, Friedman, 1988) entre a gengiva e o dente, que causa retração da gengiva marginal e o desenvolvimento de um ambiente ideal para o crescimento na superfície da raiz do dente e na camada mais externa do cemento de bactérias anaeróbias e outros microrganismos responsáveis pela doença (Seymour, Heasman, 1992; Perioli et al., 2004). Em um sulco gengival normal, o espaço entre a gengiva e o dente mede entre 1 a $3 \mathrm{~mm}$ de profundidade. Entretanto, durante a peridodontite, a profundidade da bolsa excede $5 \mathrm{~mm}$, podendo chegar a 12 mm (Medlicott et al., 1994). Além disso, em sítios saudáveis do periodonto ocorre a presença de pequenas quantidades de fluido crevicular gengival $(0,04 \mu \mathrm{L})$, com baixas taxas de fluxo $(0,03 \mu \mathrm{L} / \mathrm{min})$ e concentração de proteínas similar ao fluido extracelular (Hattingh, Ho, 1980). Por outro lado, nos sítios doentes há um aumento na produção de fluido e a composição protéica é semelhante à do soro, indicando a formação de exsudato nesses locais. O volume e a taxa de fluxo depende do grau da infecção e da inflamação em cada local. Volumes de $0,5 \mu \mathrm{L}$ e fluxos de $0,5 \mu \mathrm{L} / \mathrm{min}$ a $0,9 \mu \mathrm{L} / \mathrm{min}$ têm sido freqüentemente relatados (Hattingh, Ho, 1980; Goodson, 1989; Stoltze, 1992), podendo alcançar valores de $150 \mu \mathrm{L} / \mathrm{h}$ (Steinberg, Friedman, 1988).

Como a especificidade do biofilme dental em relação à infecção na doença periodontal é fato evidente (Gabarra, 2002), o combate às bactérias, a adequação do meio e a prevenção são fatores primordiais na restituição da saúde (Loesche, 1976; Slots, 1976; Addy, 1986; Greenstein et al., 1986; Quee, 1989; Williams, Howell, 1993, Medlicott et al., 1994; Newman, 1995). Assim, o tratamento periodontal tem por objetivo a cura do tecido inflamado, a redução do número de bactérias patogênicas e a eliminação da bolsa (Steinberg, Friedman, 1988). O tempo torna o tratamento progressivamente mais difícil, necessitando de procedimentos terapêuticos cada vez mais agressivos e complexos. Estudos evidenciaram diferenças marcantes entre as metodologias e as substâncias utilizadas para o combate da moléstia periodontal (Gabarra et al., 2002). Assim, o tratamento periodontal tradicional consiste no controle do biofilme subgengival, através de um meticuloso desbridamento periódico da bolsa (curetagem), raspagem e aplainamento radicular, realizado pelo dentista, associado ao controle da placa supragengival, através de cuidados domiciliares por parte do paciente (Helldén et al., 1979; Lindhe, Nyman, 1984; Holborow, 1986; Joyston-Bechal, Emslie, 1987; Ramfjord, 1987; Van Der Ouderaa, 1991).

Agentes antiinflamatórios esteróides (glicocorticóides) e não-esteróides (salicilatos, pirazolonas, derivados da pirazolona, derivados do ácido fenilpropiônico, derivados do ácido antranílico e derivados do ácido fenilacético) têm sido estudados e utilizados como adjuvantes ao tratamento mecânico de limpeza realizado pelo dentista (Seymour; Heasman, 1992; Jones et al., 1999). No entanto, muitas vezes o objetivo desse tratamento não é alcançado por problemas anatômicos e/ou técnicos, como a formação de nichos de microrganismos entre as raízes dentais e a capacidade de alguns destes em adentrarem nos tecidos conjuntivos, dificultando e/ou impossibilitando o acesso durante os procedimentos mecânicos de limpeza e raspagem radicular (Okuda et al., 1992; Kinane, Radvar 1999). Quando a eliminação da bolsa não é alcançada por estes métodos, a cirurgia é utilizada para remover o tecido necrótico e reduzir a profundidade da bolsa (Steinberg, 
Friedman, 1988). Essas limitações da terapêutica permitem que bolsas refratárias ao tratamento se reativem, fato que tem levado cientistas a procurarem solução alternativa com o tratamento medicamentoso com repetidas administrações de agentes antimicrobianos com ação sistêmica ou local (Loesche, 1976; 1979; Deasy et al., 1989; Turnbull, 1989; Friedman, Steinberg, 1990; Ainamo et al., 1992; Giordano et al., 1992; Jones et al., 1992; Thomson et al., 1992; Rethman et al., 1995; Kinane, Radvar, 1999; Jorgensen, Slots, 2000).

Vários autores têm descrito o uso de antimicrobianos na doença periodontal (Genco, 1981; JoystonBeechal, Emslie, 1987; Turnbull, 1989; Seymour, Heasman, 1992; Baakilini et al., 1996; Murray et al., 1997; Park et al., 1998; Eley, 1999; Gebara, 1999; Manara et al., 1999; Santos et al., 1999; Koo et al., 2000; Hirasawa et al., 2002; Sastravaha et al;. 2003), com a obtenção de efeitos clínicos e microbiológicos importantes (Norkiewicz et al., 2001; Lopez et al., 2002; Pavia et al., 2003, 2004; Rodrigues et al., 2004). Esses fármacos quando administrados no local ou sistemicamente, são eficazes em reduzir a patogenicidade da microbiota subgengival, melhorando a resposta clínica do tratamento periodontal (Seymour, Heasman, 1992).

A administração de antimicrobianos de ação sistêmica demonstrou que concentrações terapêuticas são alcançadas no sítio da infecção por curtos períodos de tempo após uma dose simples (Medlicott et al., 1994). No entanto, ela não pode ser utilizada por um longo período de tempo. Muitos efeitos colaterais indesejáveis podem surgir, tais como náuseas, vômito, diarréia, gastrite, úlceras, outros transtornos digestivos, alergias e desenvolvimento de resistência pelos microrganismos (Friedman, Golomb, 1982; Addy, Langeroudi, 1984; Brook, Van Noort, 1984; Addy, 1986; Joyston-Bechal, Emslie, 1987; Friedman, Steinberg, 1990; Greenstein, 1995; Tinoco et al., 1998), diminuindo a razão risco/benefício para um ponto no qual este tipo de tratamento não pode ser aceitável (Steinberg, Friedman, 1988; Ciancio, 1996). Assim, a liberação de fármaco intrabolsa periodontal, uma categoria especial de liberação local na cavidade oral (Medlicott et al., 1994), é geralmente utilizada no tratamento de doenças periodontais (Soskolone, Freidman, 1996). A administração do fármaco no interior da bolsa periodontal é uma alternativa para minimizar a distribuição deste no organismo e, por conseguinte, aumentar a sua concentração no local a ser tratado e diminuir os efeitos adversos indesejáveis (Steinberg, Friedman, 1988; Perioli et al., 2004).

Bochechos, irrigações e jatos pulsáteis não penetram além de 1 a $2 \mathrm{~mm}$ abaixo da margem gengival (Ito et al., 1980; Pitcher et al., 1980; Badersten et al., 1981;
Friedman, Golomb, 1982; Yeung et al., 1983). O tempo de permanência de soluções de agentes antibacterianos diretamente no interior da bolsa periodontal é curto, mesmo utilizando dispositivos de irrigação adequados (Greenstein, 1987), portanto, administrações freqüentes são requeridas para a manutenção das concentrações na bolsa periodontal (Medlicott et al., 1994). Dessa maneira, a aderência ao tratamento por parte do paciente é um fator limitante para assegurar a eficácia clínica do tratamento. Devido a todos esses problemas, atenção tem sido dada no desenvolvimento de verdadeiros sistemas de liberação de fármaco intrabolsa periodontal (SLIBP) (Ranadive, Bhat, 1998; Kinane, 2000). Assim, o objetivo do presente trabalho é revisar a literatura relacionada com esses sistemas.

\section{VANTAGENS E DESVANTAGENS}

A bolsa periodontal é um reservatório natural que permite a inserção de um dispositivo de liberação, sendo que os benefícios que podem ser adquiridos baseiam-se na liberação do agente terapêutico no local a ser tratado e a manutenção dos níveis adequados de fármaco por um período estabelecido de tempo (Steinberg, Friedman, 1988). Goodson et al. (1979) foram os primeiros a desenvolver um SLIBP, sugerindo que a utilização de um supositório de liberação controlada de um fármaco colocado na bolsa poderia ser altamente efetiva para a administração de agentes antibacterianos na terapia periodontal.

Desde então, número crescente de sistemas biodegradáveis ou não tem sido desenvolvido com o objetivo de proporcionar liberação prolongada e/ou controlada de antimicrobianos, em concentração adequada, no interior da bolsa periodontal.

Quando os objetivos acima são alcançados, o SLIBP oferece muitas vantagens (Steinberg, Friedman, 1988; Soskolone, Freidman, 1996):

- possibilita o controle e monitoramento dos níveis de fármaco no sítio de aplicação;

- é um meio útil de liberar na cavidade oral um fármaco que não é absorvido no sistema gastrintestinal (por exemplo, clorexidina);

- possibilita a obtenção de altas concentrações de fármaco no local a ser tratado, quando comparadas com os níveis plasmáticos após a administração oral;

- pode mascarar o sabor e odor desagradável de determinados fármacos e evitar o aparecimento de manchas nos dentes.

Por outro lado, deve ser considerada, a dificuldade (impossibilidade) de interrupção rápida da ação farmacológica, em caso de irritação ou intolerância. Além 
disso, existem outras desvantagens (Ansel et al., 2000; Soskolone, Freidman, 1996):

- a reprodutibilidade da ação depende da taxa do fluxo crevicular gengival e das condições anatomopatológicas da bolsa periodontal;

- a cinética de liberação depende da integridade da forma farmacêutica;

- o tamanho da preparação às vezes é muito grande;

- a biodisponibilidade reduzida, devido ao baixo fluxo;

- os custos mais elevados que os das formas farmacêuticas convencionais.

\section{PROPRIEDADES}

No desenvolvimento de SLIBP devem ser consideradas as características anatomo-fisiológicas da bolsa periodontal, pois ela é naturalmente irrigada pelo fluído crevicular gengival. Em pessoas com doença periodontal a taxa média de fluxo do fluido crevicular em sítios individuais está aumentada. Geralmente, um fluxo alto resultará em uma difusão mais rápida do fármaco do dispositivo de liberação, enquanto que um fluxo mais baixo retarda essa depleção. Assim, a taxa de liberação deve ser mais alta no estágio inicial da liberação, para que seja atingido o nível terapêutico o mais rápido possível, mantendo-se durante todo o período de tratamento (Steinberg, Friedman, 1988).

Um outro parâmetro a ser considerado é a absorção do fármaco. Um fármaco com baixa capacidade de penetração através dos tecidos da mucosa pode alcançar altas concentrações e prolongar esses níveis elevados no interior da bolsa (Steinberg, Friedman, 1988).

O tamanho e a profundidade da bolsa são importantes na formulação do sistema. Desde que a profundidade média de uma bolsa é de 5 a $12 \mathrm{~mm}$ (Medlicott et al., 1994), o sistema não pode ser grande. Assim, é necessário que a dose do agente ativo contida no mesmo seja altamente efetiva, e que este seja altamente específico, evitando, por exemplo, recidivas e o aparecimento de cepas resistentes (Steinberg, Friedman, 1988).

Além disso, o dispositivo (Steinberg, Friedman, 1988; Medlicott et al., 1994; Soskolone, Freidman, 1996): - deve ser de fácil aplicação por parte do profissional (dentista);

- não deve ser volumoso e nem causar desconforto ou irritação;

- deve possuir características físicas que facilitem a inserção rápida dentro da bolsa, causando o mínimo de dor ao paciente;

- não pode ser exposto além da margem gengival;
- não deve causar interferência na higiene oral diária normal do paciente, a qual inclui escova e fio dental;

- não pode gerar problema no padrão de dieta normal do paciente;

- deve ser prontamente aceito pelo paciente.

\section{CLASSIFICAÇÃO}

Um SLIBP pode ser classificado em biodegradável e não-biodegradável, dependendo do material envolvido na sua concepção (Soskolone, Freidman, 1996). Dispositivos que não são biodegradáveis possuem a vantagem de permitir o controle do tempo de exposição do ambiente da bolsa ao fármaco. Entretanto, a principal limitação desse tipo de dispositivo é a necessidade de remoção do mesmo após o período de tratamento e vários problemas têm sido associados a esse procedimento (Medlicott et al., 1994). Normalmente é necessária competência técnica para assegurar a retirada completa do dispositivo vazio, devido à possibilidade do aparecimento de efeitos indesejáveis, tais como inflamação do tecido local, resultantes do reconhecimento pelo sistema imune de um corpo estranho (fragmentos). Além disso, a remoção do dispositivo é acompanhada por um rápido declínio na concentração antibacteriana (Tonetti et al., 1990), o qual está freqüentemente associado com recolonização da bolsa periodontal. Por outro lado, os dispositivos biodegradáveis possuem a grande vantagem do paciente necessitar de apenas uma visita ao dentista para a inserção do dispositivo, que não precisa ser retirado, havendo diminuição das visitas clínicas e assegurando melhor adesão do paciente ao tratamento (Steinberg, Friedman, 1988; Bromberg et al., 2001).

A partir das últimas três décadas do século passado até os dias de hoje, vários sistemas reservatórios ou matriciais foram investigados (Medlicott et al., 1994). Sistemas do tipo reservatório são constituídos por um núcleo contendo o fármaco no estado sólido ou líquido, revestido por uma membrana ou parede permeável. Já em um sistema de liberação matricial o fármaco é distribuído através do polímero ou mistura de polímeros, de natureza química e propriedades variáveis, sendo que a liberação ocorre através da difusão e/ou dissolução ou erosão da matriz (Ansel, 2000). Os dispositivos nos quais a liberação ocorre apenas por difusão, são preparados utilizando-se polímero ou mistura de polímeros insolúveis em água e não-biodegradáveis (Addy et al., 1982; Goodson et al., 1983; Friedman, Golomb, 1982). Por outro lado, os dispositivos matriciais em que a liberação do fármaco ocorre por difusão e erosão ou disso- 
lução da matriz são compostos por polímeros hidrossolúveis ou biodegradáveis (Medlicott et al., 1994).

Quanto à forma, além dos tubos ocos de acetato de celulose, também chamados de fibras, os SLIBP podem ser classificados em filmes, dispositivos injetáveis e híbridos (Medlicott et al., 1994; Soskolone, Freidman, 1996).

\section{Fibras}

Fibras são dispositivos semelhantes a uma linha e foram introduzidas por Goodson et al. (1979), com a utilização de tubos de diálise para a liberação de tetraciclina no interior da bolsa periodontal. Apesar do sistema demonstrar efeitos clínicos importantes (Lindhe et al., 1979), não prolongava os níveis terapêuticos do fármaco pelo tempo suficiente para ser útil clinicamente (Goodson et al., 1985). Estudos similares utilizando fibras para a liberação de gluconato de clorexidina (Coventry, Newman, 1982) e de metronidazol (Wan Yusof et al., 1984) resultaram em conclusões similares.

Por outro lado, fibras de silicone contendo metronidazol foram eficazes, prolongando a liberação do fármaco intrabolsa periodontal por mais de dez dias (Feres Filho et al., 1990).

Vários outros estudos foram realizados (Goodson et al., 1979; 1985; Lindhe et al., 1979; Coventry, Newman, 1982; Wan Yusof et al., 1984), os quais demonstraram a eficiência das fibras em reduzir a profundidade das bolsas periodontais e o sangramento, com um significativo aumento do nível de adesão do epitélio (Newman et al., 1984; Tonetti et al., 1990). Estes levaram ao desenvolvimento de um sistema de liberação disponível comercialmente (Actisite ${ }^{\circledR}$, Alza Corporation), baseado em uma fibra monolítica de acetato de etilenovinila para a liberação de tetraciclina (Soskolone, Freidman, 1996). A fibra é inserida ao redor da circunferência do dente, aprofundando-a na bolsa periodontal (fundo), através de várias voltas para preencher completamente a bolsa. Trata-se de um processo demorado (7 a 10 minutos por dente), necessitando de artifícios, como a cola de cianoacrilato, para reter o dispositivo dentro da bolsa pelo período do tratamento.

Por não serem biodegradáveis, estas fibras possuem como desvantagem a necessidade de, pelo menos, duas visitas ao dentista, uma para inserção e outra para a remoção do dispositivo (Soskolone, Freidman, 1996; Minabe et al., 2000). No entanto, nos últimos anos a utilização de fibras tem sido alvo de estudos. Ahuja et al. (2003) prepararam fibras de acetato de etilenovinila carregadas com amoxacilina triidratada utilizando a técni- ca de melt spinning. Essas foram efetivas no controle de liberação de amoxacilina. Fibras carregadas com tetraciclina foram avaliadas clinicamente, demonstrando o melhor desempenho da resposta clínica à raspagem e aplainamento radicular em pacientes com periodontite agressiva (Friesen et al., 2002; Sakellari et al., 2003; Aimetti et al., 2004).

Filmes

A forma farmacêutica mais utilizada para os sistemas de liberação intrabolsa é a de filme, que possui propriedades físicas vantajosas para a utilização no interior da bolsa periodontal (Soskolone, Freidman, 1996):

- a dimensão e formato podem ser facilmente controlados para corresponderem às dimensões da bolsa a ser tratada;

- pode ser inserido rapidamente na bolsa com o mínimo desconforto ao paciente;

- pode ser inserido na base da bolsa, ficando totalmente submergido;

- se a espessura do filme não exceder $400 \mu \mathrm{m}$, e se possuir adesividade suficiente, ele permanecerá submergido, não interferindo nos hábitos alimentares e de higiene oral do paciente.

Os filmes podem ser constituídos por polímeros biodegradáveis ou não.

\section{Filmes não-biodegradáveis}

Um estudo comparativo entre filme de polietilmetacrilato, um polímero não-biodegradável, e tubos de diálise foi realizado, usando como agentes ativos clorexidina, metronidazol e tetraciclina (Addy et al., 1982). As investigações foram conduzidas tanto in vitro como in vivo. Os filmes foram obtidos por moldagem sob alta pressão e cortados em tamanhos adequados. Várias quantidades de agentes ativos foram acrescentadas ao filme de polietilmetacrilato, enquanto que os tubos de diálise foram preenchidos apenas com clorexidina. Nos ensaios in vitro, cada filme de acrílico e cada tubo de diálise foram colocados, separadamente, em tubos de ensaio, ficando imersos em $1 \mathrm{~mL}$ de água destilada, sendo incubados a $37^{\circ} \mathrm{C}$ durante 24 horas. Após esse período, o dispositivo era transferido para um novo tubo com o mesmo volume de água destilada $(1 \mathrm{~mL})$, o qual era novamente incubado. O fármaco liberado foi quantificado por espectrofotometria na região do ultravioleta. Esse protocolo foi repetido diariamente durante 14 dias. No estudo in vivo, os dispositivos foram inseridos em bolsas periodontais 
selecionadas de 4 voluntários portadores de periodontite avançada, retirados a cada 5 dias e colocados em placas de ágar-sangue semeado com amostras do biofilme subgengival coletado dos próprios pacientes no início do tratamento, para verificação do halo de inibição. Concluíram que os tubos de diálise liberavam muito rapidamente o fármaco e que as tiras de acrílico, com 30, 40 e 50\% de fármaco, são mais indicadas para esse tipo de tratamento produzindo halos de inibição e liberação por 14 dias.

Investigações clínicas e microbiológicas de filmes contendo $30 \%(\mathrm{p} / \mathrm{p})$ de fármaco demonstraram que os filmes com metronidazol eram mais efetivos (Yeung et al., 1983; Addy, Langeroudi, 1984; Addy et al., 1988). Essas evidências foram confirmadas por Newman et al. (1984), mas esse sistema não foi desenvolvido para a utilização clínica (Soskolone, Freidman, 1996).

Posteriormente, Friedman e Golomb (1982) avaliaram filmes de etilcelulose quanto à capacidade de liberação lenta de clorexidina. Os filmes de etilcelulose foram obtidos por evaporação do solvente, sem e com polietilenoglicol, utilizando-se clorofórmio ou etanol, acrescentados lentamente ao polímero e agitando até sua completa dissolução, quando então era acrescentada a clorexidina. Para se avaliar a liberação do fármaco, os filmes foram cortados em pequenos círculos, presos a uma película de parafina e colocados em um reservatório com um volume pré-determinado de água, aquecida a $37^{\circ} \mathrm{C}$. Periodicamente a solução era substituída e a quantidade de clorexidina liberada foi determinada por espectrofotometria na região do ultravioleta. Em 205 dias, os dispositivos contendo 5, 10 e $20 \%$ de clorexidina liberaram, 20,30 e 60\% da carga, respectivamente. No entanto nas membranas contendo aditivos, a maior parte de fármaco liberado (95\%) ocorreu nos primeiros 10 dias. Portanto, a adição de polietilenoglicol, etanol ou clorofórmio à etilcelulose provocou aumento na porosidade da matriz e na liberação de clorexidina. Os autores concluíram que o dispositivo poderia ser útil no controle do biofilme, forrando bases de próteses e aparelhos ortodônticos removíveis. Outra utilidade seria liberação do medicamento dentro de bolsas periodontais.

Filmes contendo clorexidina (Friedman, Golomb, 1982; Stabholz et al., 1986; 1991), metronidazol (Golomb et al., 1984), minociclina (Elkayan et al., 1988) e tetraciclina (Stabholz et al., 1989) foram desenvolvidos e testados. A liberação do agente terapêutico a partir desses filmes foi dependente do solvente utilizado, da presença de plastificante, da natureza e concentração de fármaco e das dimensões físicas do filme.

\section{Filmes biodegradáveis}

Vários dispositivos na forma de filmes, preparados a base de polímeros biodegradáveis, têm sido avaliados experimentalmente (Soskolone, Freidman, 1996). Dispositivos reabsorvíveis de hidroxietilproprilcelulose para a liberação de tetraciclina e clorexidina (Noguchi et al., 1984) e de ofloxacino (Higashi et al., 1990; Kimura et al., 1991) foram testados clinicamente, obtendo-se bons resultados.

Noguchi et al. (1984) foram os primeiros a desenvolver um SLIBP biodegradável. Utilizando-se filmes de hidroxipropilcelulose, eles conseguiram liberação rápida in vitro dos fármacos ( 2 horas), com máximo de dissolução do filme em três horas. In vivo, observou-se retenção de tetraciclina nas bolsas por período de 24 horas. Modificando os sistemas, através da incorporação de partículas levemente solúveis de copolímero do ácido metacrílico no filme de hidroxipropilcelulose, a liberação do ofloxacino foi prolongada, com liberação in vitro de $70 \%$ do mesmo em oito horas. In vivo, níveis acima de $2 \mu \mathrm{g} / \mathrm{mL}$ de ofloxacino foram mantidos por sete dias depois do tratamento com o dispositivo. Duas aplicações semanais desse dispositivo resultaram em reduções significativas no número de espiroquetas e organismos com motilidade na bolsa periodontal, quando comparado ao placebo. Um novo tratamento dessas mesmas bolsas com os filmes após procedimento clínico demonstrou maior redução na flora microbiana, mas as alterações não foram significativamente diferentes do controle.

Deasy et al. (1989), usando filmes biodegradáveis à base de ácido polidroxibutírico contendo tetraciclina ou metronidazol, demonstraram, in vitro, que aumentando a concentração do fármaco no dispositivo, ocorre aumento proporcional do fármaco liberado, sendo que a tetraciclina foi liberada mais lentamente que o metronidazol. Após os primeiros 5 dias, os filmes tornaram-se bastante frágeis. In vivo, o índice de placa, a inflamação e a profundidade de sondagem diminuíram em todos os grupos tratados. Entretanto, houve tendência à recidiva após aproximadamente dois meses do término do tratamento. Nas bolsas tratadas com metronidazol, o número de espiroquetas se manteve baixo por mais tempo que o grupo tratado com aplainamento radicular. Os autores concluíram que o tratamento com dispositivos de liberação lenta, usando tetraciclina ou metronidazol, se mostrou efetivo como coadjuvante no tratamento das periodontites e que, no futuro, poderão ser utilizados rotineiramente pelos dentistas.

A partir desse momento, vários polímeros biodegradáveis começaram a ser testados como filmes para a 
QUADRO 1- Filmes biodegradáveis estudados para a utilização com sistemas intrabolsa na doença periodontal

\begin{tabular}{|c|c|c|}
\hline Material & Fármaco & Referência \\
\hline Poli( $\varepsilon$-caprolactona $)$ & Clorexidina & $\begin{array}{l}\text { Goodson et al., 1983; } \\
\text { Dunn, Perkins, } \\
\text { Goodson, } 1983\end{array}$ \\
\hline $\begin{array}{l}\text { Hidrolisado de gelatina de origem } \\
\text { bovina (proteína Byco) reticulada com } \\
\text { formaldeído (Periochip }{ }^{\circledR} \text { ) }\end{array}$ & Clorexidina & $\begin{array}{l}\text { Steinberg et al., 1990; } \\
\text { Soskolone et al., } 1998\end{array}$ \\
\hline Atelocolágeno & Tetraciclina & Minabe et al., 1989a,b,c \\
\hline Poli( $\varepsilon$-caprolactona $)$ & Clorexidina & Medlicott et al., 1992 \\
\hline Teflon & Clorexidina & Kozlovsky et al., 1992 \\
\hline Colágeno & Metronidazol & Hitzig et al., 1994 \\
\hline Teflon & Cloreto de cetilpiridínio & Kozlovsky et al., 1994 \\
\hline Poli( $\varepsilon$-caprolactona) e segmentos éter-amida & Metronidazol & Quaglia et al., 2002 \\
\hline
\end{tabular}

liberação prolongada de fármaco na bolsa periodontal (Quadro 1).

\section{Sistemas injetáveis}

A possibilidade de injeção de um SLIBP é muito vantajosa (Soskolone, Freidman, 1996). Trata-se de um procedimento relativamente simples com pouco ou nenhum desconforto associado com a inserção da forma farmacêutica (Needleman, 1991). A natureza fluida inicial das formulações, a qual é necessária para a sua utilização com uma seringa, permite que a formulação tenha acesso a toda região no interior da bolsa. Para ser retida na bolsa, a formulação deve sofrer um aumento de viscosidade, evitando que a mesma seja lavada pelo fluxo do fluido crevicular gengival e pela saliva (Medlicott et al., 1994).

\section{Pomadas}

As primeiras investigações realizadas na tentativa de desenvolvimento de um SLIBP utilizavam pomadas lipofílicas, principalmente de vaselina, contendo tetraciclina (Eckles et al., 1990) ou minociclina (Nakagawa et al., 1991; Van Steenberghe, et al., 1993). Os resultados constataram diminuição significativa na proporção do número de microrganismos periodontopatogênicos, da profundidade das bolsas e uma vantajosa associação do dispositivo aos procedimentos clínicos de limpeza e aplainamento radicular.

No entanto, as pomadas mostraram propriedades de liberação prolongada de fármaco (Soskolone, Freidman, 1996). Roskos et al. (1995) desenvolveram um gel hidrofóbico, passível de bioabsorção (poli orto-éster), enriquecido com $0,5 \%$ de hidróxido de magnésio para retardar a liberação do fármaco tetraciclina. $\mathrm{O}$ início da liberação in vitro ocorreu após 24 horas e a adição de hidróxido de magnésio prolongou o tempo de liberação, melhorando o desempenho do produto para uso clínico, tendo sido considerado um dispositivo promissor.

\section{Géis hidrofílicos}

O mesmo problema de liberação rápida do fármaco foi citado para os dispositivos na forma de géis hidrofílicos (Needleman, 1991). Apesar disso, o número de investigações utilizando esse tipo de dispositivo cresceu rapidamente (Quadro 2).

\section{Precursores de fase cristalina líquida}

Quando o sistema é facilmente aplicado no interior da bolsa periodontal, adere à mucosa e, ao entrar em contato com o fluido crevicular ou saliva, se transforma em um estado cristalino líquido (consistência semi-sólida), esses sistemas são denominados de precursores de fase cristalina líquida. Este sistema foi muito estudado e está disponível comercialmente no mercado mundial sob o nome de Elyzol ${ }^{\circledR}$ (Dumex, Copenhagen, Dinamarca) (Dumex, 2003). A concentração de benzoato de metronidazol na formulação é de $40 \%(\mathrm{p} / \mathrm{p})$, equivalente a $25 \%$ de metronidazol. A solubilidade do fármaco e sua concentração influenciam o perfil de liberação. Concentrações de 103 a $1297 \mu \mathrm{g} / \mathrm{mL}$ de metronidazol foram observadas em bolsas inflamadas tratadas com este dispositivo, com do- 
QUADRO 2- Géis hidrofílicos estudados para a utilização como SLIBP na doença periodontal

\begin{tabular}{|c|c|c|}
\hline Material & Fármaco & Referência \\
\hline Ácido poli(D,L-lático-co-glicólico) & Tetraciclina & Maze et al., 1996 \\
\hline $\begin{array}{l}\text { Poloxamer } 407 \text { com polivinilpirrolidona, } \\
\text { metilcelulose ou hidroxipropilmetil celulose }\end{array}$ & Melanotan- $1^{\circledR}$ & Bhardwaj, Blanchard, 1996 \\
\hline Poloxamer & Tetraciclina & Espostio et al., 1996 \\
\hline Hidroxietilcelulose, polivinilpirrolidona e policarbofil & Tetraciclina & Jones et al., 1996 \\
\hline Hidroxietilcelulose e Carbopol ${ }^{\circledR}$ & Metronidazol & Jones et al., 1997 \\
\hline Álcool polivinílico & Metronidazol & Mallapragada et al., 1997 \\
\hline Copolímero bioerodível & Tetraciclina & Needleman et al., 1998 \\
\hline Gelatina, ácido poliglutâmico e uréia & - & Otani et al. 1998 \\
\hline $\begin{array}{l}\text { Poloxamer, hidroxipropilmetil celulose, } \\
\text { carboximetilcelulose ou dextrano }\end{array}$ & Lidocaína ou ibuprofeno & Paavola et al. 1998 \\
\hline $\begin{array}{l}\text { Hidroxietilcelulose, polivinilpirrolidona } \\
\text { e policarbofil }\end{array}$ & Flurbiprofeno & Jones et al., 1999 \\
\hline Poloxamer 188 e 407 & Prilocaína e lidocaína & Scherlund et al., 2000 \\
\hline $\begin{array}{l}\text { Hidroxietilcelulose, } \\
\text { polivinilpirrolidona e policarbofil }\end{array}$ & Tetraciclina & Jones et al., 2000, 2001 \\
\hline $\begin{array}{l}\text { Ácido poli(D,L-lático-co-glicólico), } \\
\text { etilcelulose, carboximetilcelulose, } \\
\text { carbopol } 971^{\circledR}, \text { nitrato de prata } \\
\text { e amido de milho }\end{array}$ & $\begin{array}{l}\text { Benzilpenicilina, } \\
\text { aciclina, sulfadiazina de prata }\end{array}$ & Bromberg et al., 2001 \\
\hline Colágeno & Clorexidina & Vinholis et al., 2001 \\
\hline $\begin{array}{l}\text { Hidroxipropilmetilcelulose, Carbopol } 940^{\circledR} \text {, } \\
\text { Carbopol } 971^{\circledR}, \text { policarbofil, } \\
\text { hidroxipropilmetilcelulose K4M e K15M }\end{array}$ & Metronidazol & Perioli et al., 2004 \\
\hline Gel livre de amina & Doxiciclina & Kim et al., 2002 \\
\hline Poli (orto éster) & Tetraciclina & Schwach-Abdellaoui et al., 2002 \\
\hline Poloxamer 407 & Tetraciclina & Kelly et al., 2004 \\
\hline
\end{tabular}

ses efetivas sendo mantidas por 24 a 36 horas (Stoltze, 1992). Níveis sistêmicos de metronidazol entre 0,2 e 1,3 $\mu \mathrm{g} / \mathrm{mL}$ foram observados depois da administração de 29 a $103 \mathrm{mg}$ equivalentes de metronidazol (Stoltze, Stellfeld, 1992), concluindo-se que o sistema aplicado localmente atingiu altas concentrações nas bolsas periodontais e foi significativamente menos tóxico quando comparado à via sistêmica. A terapia recomendada é de duas aplicações em cada bolsa, com intervalo de uma semana (Klinge et al., 1992). Estudos clínicos compararam essa abordagem terapêutica isoladamente e com a raspagem e aplainamento radicular, indicando que esse dispositivo com metronidazol resultou na redução da profundidade da bolsa e do sangramento na sondagem, o que não foi significativamente diferente dos resultados obtidos apenas com a limpeza e aplainamento radicular (Pedrazzoli et al., 1992; Ainamo et al., 1992).

Os efeitos dos usos sistêmico $\left(\right.$ Flagyl $\left.^{\circledR}\right)$ e local $\left(\mathrm{Elyzol}^{\circledR}\right)$ de metronidazol foram comparados (Noyan et al.,
1997). Pacientes foram tratados com o desbridamento mecânico associado ou não com quimioterápico, por 10 dias e posteriormente monitorados por 42 dias. Todas as modalidades de tratamento apresentaram melhora clínica e redução do número de bactérias anaeróbias. Entretanto, o grupo tratado com desbridamento associado ao dispositivo de liberação prolongada mostrou-se mais prático e com menos efeitos colaterais, portanto, mais efetivo. Assim, os autores recomendaram para o tratamento de bolsas periodontais profundas o desbridamento mecânico seguido de antibioticoterapia com Elyzol ${ }^{\circledR}$.

O comportamento clínico e a reinfestação microbiológica em pacientes tratados com raspagem subgengival isolada ou associada à aplicação de $\mathrm{Elyzol}^{\circledR}$ também foi avaliada (Stelzel, Fiores-de-Jacoby, 1997). Os resultados demonstraram redução significativa dos microrganismos anaeróbios, principalmente no grupo tratado com antibiótico, melhora clínica e diminuição da profundidade da bolsa, durante os 24 meses de acompanhamento. O tratamen- 
to associado com antibiótico apresentou melhora mais rápida. Contudo, as duas modalidades de tratamento, quando bem realizadas, podem oferecer bons resultados, pois em longo prazo, não houve diferenças significativas entre os grupos tratados. Outros autores também concluíram que a utilização de tetraciclina ou metronidazol aplicados através do precursor de fase cristalina líquida, quando associados à raspagem e alisamento radicular, pode ser de grande valia na terapia periodontal (Awartani, Zulqarnain, 1998; Lie et al., 1998).

Norling et al. (1992) desenvolveram um sistema de liberação prolongada desse tipo contendo metronidazol. Trata-se de um sistema líquido composto por mistura de monoleato de glicerina e benzoato de metronidazol isenta de água, na qual um triglicerídeo, óleo de sésamo (gergelim), foi adicionado para diminuir o ponto de fusão, melhorando as características de fluxo do sistema na seringa.

\section{Híbridos}

Esses sistemas combinam as propriedades de mais de uma classe de dispositivos (Needleman, 1991). Dessa maneira, há o potencial de se poderem selecionar as características de diferentes grupos, combinando-os dentro de um único sistema.

Partículas poliméricas de copolímeros do ácido lático e ácido glicólico, de aproximadamente $0,2 \mathrm{~mm}$ de diâmetro, foram preparadas para a liberação de tetraciclina e de minociclina intrabolsa (Medlicott et al., 1994; Vandekerckhove et al., 1998). As microcápsulas contendo tetraciclina foram suspensas em um gel termosensível de poloxamer 407, o qual gelifica à temperatura corporal retendo as microcápsulas na bolsa periodontal durante todo o período de tratamento. Em animais, foi observado que o sistema manteve a concentração de tetraciclina no fluido crevicular gengival por 3 a 4 dias. Em contraste, microcápsulas de minociclina no estado seco foram administradas em bolsas periodontais de cães beagle, demonstrando que concentração efetiva de minociclina foi mantida por quatorze dias (Medlicott et al., 1994).

\section{UTILIZAÇÃO DE SISTEMAS BIOADESIVOS}

Os SLIBP podem ser bioadesivos, os quais interagem com a mucina que reveste o epitélio ou a superfície dos dentes pelos princípios da bio/mucoadesão, prolongando o tempo de retenção da formulação dentro da bolsa (Jones et al., 2000). Além disso, podem promover um íntimo contato entre a forma farmacêutica e o tecido de absorção, o qual resulta em alta concentração em uma área localizada e também, um alto fluxo de fármaco (Guo, Cooklock, 1996; Ahuja, Khar, Ali, 1997).

Os atributos desejáveis para um sistema adesivo oral para a liberação prolongada são a alta capacidade de carregamento com fármaco, boa mucoadesão, não ser irritante, ser confortável, sem sabor ou de sabor agradável e liberar o fármaco por um tempo prolongado (Martin et al., 2003). Nos anos recentes, foram sugeridas formas farmacêuticas mucoadesivas para liberação oral, tais como comprimidos, patches e sistemas semi-sólidos. Dentre elas, alguns SLIBP foram investigados.

Patches bioadesivos envolvem os sistemas mais simples como os filmes erodíveis e não-erodíveis e os mais sofisticados, que são projetados para proporcionar liberação unidirecional ou bidirecional de fármaco (Degrande et al., 1996; Guo, Cremer, 1999; Peh, Wong, 1999; Fowler et al., 2001). No entanto, os patches mais sofisticados não são adequados para a liberação de agentes ativos no interior da bolsa periodontal. A utilização de polímeros não-biodegradáveis implica a necessidade de remoção ao final da terapia, a baixa flexibilidade e elasticidade, reações imunológicas potenciais, sensibilização de tecido e dificuldade de aplicação na bolsa limitam o emprego dos mesmos (Jones et al., 1996; Wong et al., 1999). Assim, os filmes poliméricos mucoadesivos têm sido mais estudados (Friedman, Golomb, 1982; Minabe et al., 1989a,b,c; Steinberg et al., 1990; Jones; Medlicott, 1995; Matsuda et al., 1999; Peh; Wong, 1999).

Os sistemas semi-sólidos bioadesivos baseados em hidrogéis também são formas farmacêuticas altamente atrativas para a liberação intrabolsa, com a possibilidade de prolongar o tempo de residência do dispositivo e melhorar a biodisponibilidade (Chidambaram, Srivatsava, 1995; Jones et al., 1996). Vários materiais têm sido utilizados no desenvolvimento desses sistemas, tais como hidroxitetilcelulose, polivinilpirrolidona e policarbofil (Jones et al., 1996, 1999, 2000); carboximetilcelulose, metilcelulose, hidroxietilcelulose, polivinilpirrolidona, Carbopol $^{\mathbb{}}$ (Varshosaz et al., 2002) e quitosana (Ikinci et al., 2002; Martin et al., 2003; Kelly et al., 2004). Lipossomas preparados com fosfatilcolina de ovo, colesterol e estearoilamina foram revestidos com lectina (Concavalina-A) (Vyas et al., 2001). Esses lipossomas mantiveram a afinidade e a especificidade da lectina, possibilitando ação sítio-específica para o glicocálix do biofilme bacteriano.

A principal propriedade da bioadesão é a força de adesão da forma farmacêutica ao tecido biológico (Wong, 1999). Assim, vários métodos têm sido reportados na literatura para avaliar a mucoadesão na cavidade oral, estudar seus mecanismos, além de assegurar a compatibilidade, 
estabilidade física e força bioadesiva, durante o desenvolvimento dos sistemas (Bouckaert, 1993).

Um polímero bioadesivo ideal para um SLIBP deve possuir as seguintes características:

- o polímero e seus produtos de degradação devem ser atóxicos e não-absorvíveis através do tecido da bolsa;

- não deve ser irritante ou causar inflamação;

- preferencialmente formar ligação não-covalente com a mucina das superfícies epiteliais;

- deve aderir rapidamente no tecido úmido e possuir alguma especificidade local;

- deve permitir a fácil incorporação do fármaco e não oferecer impedimento à sua liberação;

- deve permitir a flexibilidade da forma farmacêutica, facilitando a inserção na bolsa com o menor desconforto possível;

- deve ser estável durante o seu tempo de estocagem ou da forma farmacêutica;

- o custo do polímero não deve ser alto, permitindo a produção de dispositivos viáveis economicamente.

Além disso, muitos polímeros mucoadesivos são capazes de inibir enzimas proetolíticas e/ou modular a permeabilidade tecidual (Lehr, 1996), podendo ser úteis no desenvolvimento de novos SLIBP.

\section{AVALIAÇÃO DA EFETIVIDADE DO TRATAMENTO DA DOENÇA PERIODONTAL}

Existem vários protocolos que têm sido empregados na avaliação da efetividade da terapia periodontal com SLIBP. Geralmente, os efeitos dos tratamentos são avaliados pela melhora clínica e alterações da microflora subgengival (Medlicott et al., 1994). A melhora clínica é avaliada por índices que refletem o grau de inflamação e de acúmulo de placas, tais como o índice de placa, índice gengival, grau de hemorragia à sondagem, profundidade da bolsa, medida do nível de adesão do epitélio juncional, medida da taxa de fluido crevicular (Seymour, Heasman, 1992). Outra avaliação importante é a microbiológica, que envolve a determinação das alterações na microflora subgengival. As bactérias coletadas são identificadas ou classificadas de acordo com sua morfologia, coloração Gram, motilidade e requerimentos de oxigênio. As proporções são calculadas para cada espécie ou grupo e alterações de populações patogênicas para não-patogênicas são observadas durante o tratamento (Medlicott et al., 1994).

Assim, o fluido crevicular gengival possui grande importância na avaliação clínica da doença periodontal e da efetividade dos sistemas de liberação de fármaco intrabolsa. Goodson (1989) calculou a taxa de renovação do fluido gengival em 40 vezes por hora e sugeriu que esta contribui para a rápida diminuição da quantidade de agente antibacteriano e pequena duração de ação do mesmo observada com o tratamento por irrigação.

A análise da concentração de fármaco no fluido crevicular gengival é o melhor método para se determinar a efetividade de um sistema de liberação. O maior problema tem o sido o desenvolvimento de ensaios com limite de detecção que permita a quantificação de agentes antibacterianos presentes em volumes pequenos $(0,5 \mu \mathrm{L})$ de fluido crevicular gengival (Medlicott et al., 1994). Assim, vários autores têm desenvolvido ensaios microbiológicos (Gordon et al., 1980; Goodson et al., 1983; Freeman et al., 1992; Higashi et al., 1991; Notten et al., 1982) e de cromatografia líquida de alta eficiência (Holborow et al., 1988; Higashi et al., 1989; Britt, Pohlod, 1986; Stoltze, 1992) para quantificação de alguns agentes terapêuticos liberados no fluido crevicular gengival a partir de SLIBP.

\section{CONCLUSÕES}

O desenvolvimento de novos sistemas de liberação de fármacos ou o aprimoramento dos já existentes é um dos desafios do século, em especial, aqueles destinados ao tratamento da bolsa periodontal devido às restrições impostas pela anatomofisiologia do local e a dificuldade da avaliação precisa de sua eficácia. Neste contexto, os filmes flexíveis e as preparações semi-sólidas bioadesivas, compostas por polímeros biodegradáveis, apresentam maior potencial de eficácia e aplicação prática.

\section{ABSTRACT}

\section{Periodontal pocket drug delivery systems}

Periodontal disease is very common in the world population. It is caused by the accumulation of microbial components of the dental biofilm inside the subgingival areas, producing an inflammatory process that affects the supporting structures of tooth, periodontal pockets and loss of the teeth, if not treated. The conventional treatment consists of tooth surface mechanical cleaning and root planning, associated or not to the systemic use of high concentrations of antibiotics, but with reduced effectiveness, and adverse effects. The patient compliance to the therapeutic is committed too. In the last decades, the treatment has been optimized for the use of drug delivery systems to the periodontal pocket, with the advantage of delivering the drug in the specific site, sustaining and/or controlling the drug concentration. Recently, the use of new drug delivery systems has been receiving great interest. This review approaches the main 
delivery systems for the administration of drugs to the periodontal pocket, their usefulness, as well as the available protocols for the evaluation of these systems effectiveness in the periodontal therapy.

UNITERMS: Periodontal diseases. Periodontal pocket. Delivery systems. Periodontal pocket delivery.

\section{AGRADECIMENTOS}

Os autores agradecem à CAPES (Coordenação de Aperfeiçoamento de Pessoal de Nível Superior) pelo apoio financeiro.

\section{REFERÊNCIAS BIBLIOGRÁFICAS}

ADDY, M. Chlorhexidine compared with other locally delivered antimicrobials. A short review. J. Clin. Periodontol., v. 13, p. 957-964, 1986.

ADDY, M.; HASSAN, H.; MORAN, J.; WADE, W.; NEWCOMBERT, R. Use of antimicrobial containing acrylic strips in the treatment of chronic periodontal disease. J. Periodontol. V. 59, n. 9, p. 557-564, 1988.

ADDY, M.; LANGEROUDI, M. Comparison of the immediate effects on the subgingival microflora of acrilyc strips containing $40 \%$ chlorhexidine, metronidazole or tetracycline. J. Clin. Periodontol., v. 11, n. 6, p. 379-386, 1984.

ADDY, M.; RAWLE, L.; HANDLEY, R.; NEWMAN, H. N.; COVENTRY, J. F. The development and in vitro evaluation of acrylic strips and dialysis tubing for local drug delivery. J. Periodontol., v. 53, n. 11, p. 693-699, 1982 .

AHUJA, A.; ALI, J.; SARKAR, R.; SHAREEF, A.; KHAR, R. K. Targeted retentive device for oro-dental infections: formulation and development. Int. J. Pharm., v. 259, p. 47-55, 2003.

AHUJA, A.; KHAR, R. K.; ALI, J. Mucoadhesive drug delivery systems. Drug Dev. Ind. Pharm., v. 23, n. 5, p. 489-515, 1997.

AIMETTI, M.; ROMANO, F.; TORTA, I.; CIRILLO, D.; CAPOSIO, P.; ROMAGNOLI, R. Debridement and local application of tetracycline-loaded fibres in the management of persistent periodontitis: results after 12 months. J. Clin. Periodontol., v. 31, p. 166-172, 2004.
AINAMO, J.; LIE, T.; ELLINGSEN, B. H.; HANSEN, B. F.; JOHANSSON, L. A.; KARRING, T.; KISCH, J.; PAUNIO, K.; STOLTZ, K. Clinical responses to subgingival application of a metronidazole $25 \%$ gel compared to the effect of subgingival scaling in adult periodontitis. J. Clin. Periodontol., v. 19, n. 9, p. 723-729, 1992.

ANSEL, H. C.; POPOVICH, N. G.; ALLEN JR, L. V. Farmacotécnica: formas farmacêuticas e sistemas de liberação de fármacos. 6 ed. São Paulo: Editorial Premier, 2000.568p.

AWARTANI, F. A.; ZULQARNAIN, B. J. Comparison of the clinical effects of subgingival application of metronidazole $25 \%$ gel and scaling in the treatment of adult periodontitis. Periodontics, v. 29, p. 41-48, 1998.

BAAKILINI, M. F.; LARA, E. H. G.; PANZERI, H. Adición de próplis en formulaciones de dentífricos. Evaluación de sus propriedades y estabilidad. Rev.Fola/Oral, n. 6, p. 130-132, 1996.

BADERSTEN, A. NILVÉUS, R.; EGELBERG, J. Effect of nonsurgical periodontal therapy I. Moderately advanced periodontitis. J. Clin. Periodontol., v. 8, p. 57-72, 1981.

BHARDWAJ, R.; BLANCHARD, J. Controlled-release delivery system for the $\alpha$-MSH analog melanotan-I using poloxamer 407. J. Pharm. Sci., v. 85, n. 9, p. 915-919, 1996.

BOLSTAD, A. I.; JENSEN, H. B.; BAKKEN, V. Taxonomy, biology, and periodontal aspects of Fusobacterium nucleatum. Clin. Microbiol. Rev., v. 9, n. 1, p. 55-71, 1996.

BOUCKAERT, S.; LEFEBVRE, R. A.; REMON, J. P. In vitro/in vivo correlation of the bioadhesive properties of a buccal bioadhesive miconazole slow-release tablet. Pharm. Res., v. 10, n. 6, p. 853-856, 1993.

BRITT, M. R.; POHLOD, D. J. Serum and crevicular fluid concentrations after a single oral dose of metronidazole. J. Periodontol., v. 57, p. 104-107, 1986.

BROMBERG, L. E.; BUXTON, D. K.; FRIDEN, P. M. Novel periodontal drug delivery system for treatment of periodontitis. J. Control. Rel., v. 71, p. 251-259, 2001. 
BROOK, I. M.; VAN NOORT, R. Controlled delivery of drugs. Br. Dent. J., v. 157, n. 11, p. 11-15, 1984.

CHIDAMBARAM, N.; SRIVATSAVA, A. K. Buccal drug delivery systems. Drug Dev. Ind. Pharm., v. 21, n. 9, p. 1009-1036, 1995.

CIANCIO, S.G. Medication as risk factors for periodontal disease. J. Periodontol., v. 67, n. 10S, p. 1055-1059, 1996.

COVENTRY, J.; NEWMAN, H. N. Experimental use of a slow release device employing chlorhexidine gluconato in areas of acute periodontal inflammation. J. Clin. Periodontol., v. 9, n. 2, p. 129-133, 1982.

DEASY, P. B.; COLLINS, A. E. M.; MACCARTHY, D. J.; RUSSEL, R. J. Use of strips containing tetracycline hydrochloride or metronidazole for treatment of advanced periodontal disease. J. Pharm. Pharmacol., v. 41, n. 10, p. 694-699, 1989.

DEGRANDE, G.; BENES, L.; HORRIÉRE, F.; KARSENTY, H.; LACOSTE, C.; MCQUINN, R.; GUO, J. H.; SCHERRER, R. Specialized oral mucosal drug delivery systems: patches. In: RATHBONE, M. J. (Ed.). Oral mucosal drug delivery. New York: Marcel Dekker, 1996, v. 74, p. 285-317.

DUMEX ORAL HEALTH CARE. Elyzol dental gel. 2003. $48 \mathrm{p}$. Monografia internacional de produto - Dumex, AIPHARMA.

DUNN, R. L.; PERKINS, B. H.; GOODSON, J. M. Controlled release of tetracycline from biodegradable fibres. J. Dent. Res., v. 62, p. 289, 1983.

ECKLES, T. A.; REINHARDT, R. A.; DYER, J. K.; TUSSING, G. J.; SZYDLOWSKI, W. M.; DUBOIS, L. M. Intracrevicular application of tetracycline in white petrolatum for the treatment of periodontal disease. $J$. Clin. Periodontol., v. 17, n. 7, p. 454-462, 1990.

ELEY, B. M. Antibacterial agents in the control of supragingival plaque - a review. Br. Dent. J., v. 186, p. 286-296, 1999.

ELKAYAM, R.; FRIEDMAN, M.; STABHOLZ, A.; SOSKOLNE, A.W.; SELA, M.N.; GOLUB, L. Sustained release device containing minocycline for local treatment of periodontal disease. J. Control. Rel., v. 7, p. 231-236, 1988.
ERHART, E. A. Elementos de anatomia humana. 7. ed. São Paulo: Atheneu, 1987. 272p.

ESPOSITO, E.; CORTESI, R.; NASTRUZZI, C. Gelatin microspheres: influence of preparation parameters and thermal treatment on chemico-physical and bio-pharmaceutical properties. Biomaterials, v. 17, p. 2009-2020, 1996.

FERES FILHO, E. J.; CHEVITARESE, O.; ZEBRAL,A.A.; VILLORIA, G. E. Desenvolvimento de um dispositivo de liberação prolongada contendo metronidazol para terapia periodontal tópica. $R B O$, v. XLVII, n. 2, p. 44-45, 1990.

FOWLER, E. B.; BREAULT, L. G.; BRYANT, J. B. Sitespecific chlorhexidine: a periodontal alternative. Gen. Dent., v. 49, n. 1, p. 84-88, 2001.

FRANK, R. M. Bacterial penetration in the apical pocket wall of advanced human periodontitis J. Periodontal Res., V. 15, n. 6, p. 563-573, 1980.

FREEMAN, E.; ELLEN, R. P.; THOMPSON, G.; WEINBERG, S. E.; SONG, M.; LAZARUS, R. H. Gingival crevicular fluid concentration and side effects of minocicline: a comparison of two regimens. $J$. Periodontol., v. 63, p. 13-18, 1992.

FRIEDMAN, M.; GOLOMB, G. New sustained release dosage form of chlorhexidine for dental use. Idevelopment and kinetics of release. J. Periodontal Res., v. 17, n. 3, p. 323-328, 1982.

FRIEDMAN, M.; STEINBERG, D. Sustained release delivery systems for treatment of dental diseases. Pharm. Res., v. 7, n. 4, p. 313-317, 1990.

FRIESEN, L. R.; WILLIAMS, K. B.; KRAUSE, L. S.; KILLOY, W. J. Controlled local dleivery of tetracycline with polymer strips in the treatment of periodontitis. $J$. Periodontol., v. 73, n. 1, p. 13-19, 2002.

GABARRA, F. R. Dispositivo mimetizador de bolsa periodontal para estudos in vitro de liberação de fármaco. 2002. $197 \mathrm{f}$. [Tese de Doutorado. Faculdade de Odontologia de Ribeirão Preto, Universidade de São Paulo].

GEBARA, E. C. E.; LIMA, L.A.; MAYER, M.P. A. Propolis antimicrobial activity agaisnt periodontopathic bacteria. Braz. J. Microbiol., v. 33, p. 365-369, 2002. 
GENCO, R. J. Antibiotics in the treatment of human periodontal diseases. J. Periodontol., v. 52, p. 545-558, 1981.

GIORDANO, J.; LOESCHE, W. J.; WALSH, L.; AMALFITANO, J. Effect of local delivery of metronidazole or chloehexidine in periodontitis patients. J. Dent. Res., v. 71, p. 319, 1992.

GOLOMB, G.; FRIEDMAN, M.; SOSKOLONE, W. A.; STABHOLZ, A.; SELA, M. N. Sustained release device containing metronidazole for periodontal use. J. Dent. Res., v. 63, n. 9, p. 1149-1153, 1984.

GOODSON, J. M. Pharmacokinetic principles controlling efficacy of oral therapy. J. Dent. Res., v. 68, p. 1625-1632, 1989.

GOODSON, J. M.; HAFFAJEE, A.; SOCRANSKY, S. S. Periodontal therapy by local delivery of tetracycline. $J$. Clin. Periodontol., v. 6, n. 2, p. 83-92, 1979.

GOODSON, J. M.; HOLBOROW, D.; DUNN, R. L.; HOGAN, P.; DUNHAM, S. Monolithic tetracyclinecontaining fibres for controlled delivery to periodontal pockets. J. Periodontol., v. 54, p. 575-579, 1983.

GOODSON, J. M.; OFFENBACHER, S.; FARR, D. H.; HOGAN, P. E. Periodontal disease treatment by local drug delivery. J. Periodontol., v. 56, p. 265-272, 1985.

GORDON, J. M.; WALKER,C. B.; GOODSON, J. M.; SOCRANSKY, S.S. Sensitive assay for measuring tetracycline levels in gingival crevice fluid. Antimicrob. Agents Chemother., v. 17, p. 193-198, 1980.

GREENSTEIN, G. Clinical significance of bacterial resistance to tetracyclines in the treatment of periodontal diseases. J. Periodontol., v. 66, n. 11, p. 925-932, 1995.

GREENSTEIN, G. Effects of subgengival irrigation on periodontal status. J. Periodontol., v. 58, p. 827-836, 1987.

GREENSTEIN, G.; BERMANT, C.; JAFFINT, R. Chlorhexidine, an adjunct to periodontal therapy. $J$. Periodontol., v. 57, n. 6, p. 370-376, 1986.

GUO, J. H.; COOKLOCK, K. M. The effects of backing materials and multilayered systems on the characteristics of bioadhesive buccal patches. J. Pharm. Pharmacol., v. 48, p. 255-257, 1996.
GUO, J. H.; CREMER, K. Development of bioadhesive buccal patches. In: Mathiowitz, E.; Chickering, D. E.; Lehr, C. M. (Ed.), Bioadhesive drug delivery systems. New York:Marcel Dekker, v. 98, p. 541-562, 1999.

GUYTON, A. C. Tratado de fisiologia médica. 7. ed. Rio de Janeiro: Guanabara Koogan, 1989. 830p.

HATTINGH, J.; HO, E. The concentration of proteins in human gingival crevicular fluid. J. Periodontol. Res., v. 15 , p. $90-95,1980$

HELLDÉN, L. B.; LISTGARTEN, M. A.; LINDHE, J. The effect of tetracycline and/or scaling on human periodontal disease. J. Clin. Periodontol., v. 6, p. 222-230, 1979.

HIGASHI, K.; MATSUSHITA, M.;MORISAKI, K.; HAYASHI, S.; MAYUMI, T. Local drug delivery systems for the treatment of periodontal disease. $J$. Pharmacobio-Dyn., v. 14, p. 72-81, 1991.

HIGASHI，K.; MORISAKI，K.; HAVASHI， S.; KITAMURA, M.; FUJIMOTO, N.; KIMURA, S.; EBISU, S.; OKADA, H. Local ofloxacin delivery using a controlled-release insert in the human periodontal pocket. J. Periodontal Res., V. 25, n. 1, p. 1-5, 1990.

HIGASHI, K.; SEIKE, M.; MITANI, Y.; MORISAKI, K.; HAYASHI, S.; KITAMURA, M.; FUJIMOTO, N.; KIMURA, S.; EBISU, S.; OKADA, H. Concentration of ofloxacin in human gingival crevicular fluid after oral administration of Tarivid®. J. Periodontal Res., v. 24, p. 409-411, 1989.

HIRASAWA, M.; TAKADA, K.; MAKIMURA, M.; OTAKE, S. Improvement of periodontal status by green tea catechin using a local delivery system: a clinical pilot study. J. Periodont. Res., v. 37, p. 433-438, 2002.

HITZIG, C.; CHARBIT, Y.; BITTON, C.; FOSSE, T.; TEBOUL, M.; HANNOUN, L.; VARONNE, R. Topical metronidazole as an adjunct to subgingival debridement in the treatment of chronic periodontitis. J. Clin. Periodontol., v. 21, p. 146-151, 1994.

HOLBOROW, D. W. Local delivery of antibacterial agents in the treatment of periodontal disease. New Zealand Dental J., v. 82, p. 119-121, 1986.

HOLBOROW, D. W.; GAUDIE, W.; HUNG, T.; GOODSON, J. M. Periodontal pocket concentration of tetracycline by local delivery. J. Dent. Res., Abstracts, p. $25,1988$. 
IKINCI, G.; SENEL, S.; AKINCIBAY, H.; KAS, S.; ERCIS, S.; WILSON, C. G.; HINCAL, A.A. Effect of chitosan on a periodontal pathogen Porphyromonas gingivalis. Int. $J$. Pharm., v. 235, p. 121-127, 2002.

ITO, I. Y.; ALONSO VERRI, R.; RIBAS, J. P.; MARQUES DE LIMA, S. N.; PALAMIN, R. V.; MAIA CAMPOS, G. Efeitos do cloreto de cetilpiridíniona inibição da placa dental. Odont. Moderno, p. 8-23, 1980.

JONES, A.; WOOD, R.; NEWBOLD, D.; MANWELL, M.; KORMAN, K. Clinical effects of subgingival minocycline in periodontitis. J. Dent. Res., v. 17, p. 245, 1992.

JONES, D. S.; IRWIN, C. R.; WOOLFSON, A. D.; DJOKIC, J.; ADAMS, V. Physicochemical characterization and preliminary in vivo efficacy of bioadhesive, semisolid formulations containing flurbiprofen for the treatment of gingivitis. J. Pharm. Sci., v. 88, n. 6, p. 592-598, 1999.

JONES, D. S.; MEDLICOTT, N. J. Casting solvent controlled release of chlorhexidine from ethylcellulose films prepared by solvent evaporation. Int. J. Pharm., v. 114, p. 257-261, 1995.

JONES, D. S.; WOOLFSON,A. D.; BROWN,A. F. Textural, viscoelastic and mucoadhesive properties of pharmaceutical gels composed of cellulose polymers. Int . J. Pharm., v. 151, p. 223-233, 1997.

JONES, D. S.; WOOLFSON, A. D.; BROWN, A. F.; COULTER, W. A.; MCCLELLAND, C.; IRWIN, C. R. Design, characterisation and preliminary clinical evaluation of a novel mucoadhesive topical formulation containing tetracycline for the treatment of periodontal disease. J. Control. Rel., v. 67, p. 357-368, 2000.

JONES, D. S.; WOOLFSON, A. D.; DJOKIC, J.; COULTER, W. A. Development and mechanical characterization of bioadhesive semi-solid, polymeric systems containing tetracycline for the treatment of periodontal diseases. Pharm. Res., v. 13, n. 11, p. 17341738, 1996.

JONES, D.S.; BROWN, A.F.; WOOLFSON, A.D. Rheological characterization of bioadhesive, antimicrobial, semisolids designed for the treatment of periodontal diseases: transient and dynamic viscoelastic and continuous shear analysis. J. Pharm. Sci., v. 90, n. 12, p. 1978-1990, 2001.
JORGENSEN, M.G.; SLOTS, J. Responsible use of antimicrobials in periodontics. J. Calif. Dental Assoc., p. $1-12,2000$.

JOYSTON-BECHAL, S.; EMSLIE, R. D. Topical and systemic antimicrobial agents in the treatment of chronic gingivitis and periodontitis. Int. Dent. J., v. 37, p. 52-62, 1987.

KAPLAN, A. H.; WEBER, D. J.; ODDONE, E. Z.; PERFECT, J. R. Infection due Actinobacillus actinomycetemcomitans: 15 cases and review. Rev. Infect. Dis., v. 11, n. 1, p. 46-63, 1989.

KELLY, H. M.; DEASY, P. B.; ZIAKA, E.; CLAFFEY, N. Formulation and preliminary in vivo dog studies of a novel drug delivery system for the treatment of periodontitis. Int. J. Pharm., v. 274, p. 167-183, 2004.

KIM, T. S.; BURKLIN, T.; SCHACHER, B.; RATKAKRUGER, P.; SCHAECKEN, M. T.; RENGGLI, H. H.; FIEHN, W.; EICKHOLZ, P. Pharmacokinetic profile of a locally administrated doxycicline gel in crevicular fluid, blood, and saliva. J. Periodontol., v. 73, n. 11, p. 12851291, 2002.

KIMURA, S.; TODA, H.; SHIMABUKURO, Y.; KITAMURA, M.; FUJIMOTO, N.; MIKI, Y.; OKADA, $\mathrm{H}$. Topical chemotherapy in human periodontitis using a new controlled-release insert containing ofloxacin. I Microbiological observation. J. Periodontal Res., v. 26, n. 1, p. 33-41, 1991.

KINANE, D. F. Local antimicrobial therapies in periodontal disease. Ann. R. Australas. Coll. dent. Surg., v. 15, p. 57 60, 2000.

KINANE, D. F.; RADVAR, M. A six-month comparison of three periodontal local antimicrobial therapies in persistent periodontal pockets. J. Periodontol., v. 70, n. 1, p. 1-7, 1999.

KOO, H.; GOMES, B. P. F. A.; ROSALEN, P. L.; AMBROSANO, G. M. B.; PARK, Y. K.; CURY, J. A. In vitro antimicrobial activity of propolis and Arnica montana against oral pathogens. Arch. Oral Biol., v. 45, p. 141-148, 2000.

KOSLOVSKY, A.; SINTOV, A.; MOLDOVAN, M.; TAL, $\mathrm{H}$. Inhibition of plaque formation by local aplication of a degradable controlled release system containing Cetylpyridinium chloride. J. Clin. Periodontol., v. 21, n. 1, p. 32-37, 1994. 
KOSLOVSKY, A.; SINTOV, A.; ZUBERY, Y.; TAL, H. Inhibition of plaque formation and gingivitis in beagle dogs by topical use of a degradable controlled release system containing chlorhexidine. J. Dent. Res., v. 71, n. 9, p. 1577-1581, 1992.

LEHR, C. M. From sticky stuff to sweet receptors achievements, limits and novel approaches to bioadhesion. European J. Drug Metabol. Pharmacokinetics, v. 21, n. 2, p. 139-148, 1996.

LIE, T.; BRUUN, G.; BÖE, E. Effects of topical metronidazole and tetracycline in treatment of adult periodontitis. J. Periodontol., v. 69, n. 7, p. 819-8127, 1998.

LINDHE, J.; HEIJL, L.; GOODSON, J. M.; SOCRANSKY, S. S. Local delivery using fiber devices in periodontal therapy. J. Clin. Periodontol., v. 6, p. 141-149, 1979.

LINDHE, J.; NYMAN, S. Long-term maintenance of patients treated for advanced periodontal disease. J. Clin. Periodontol., v. 11, p. 504-514, 1984.

LISTGARTEN, M. A. Pathogenesis of periodontitis. J. Clin. Periodontol., v. 13, p. 418-425, 1986.

LOESCHE, W. J. Chemotherapy of dental plaque infections. Oral Sci. Rev., v. 9, p. 65-107, 1976.

LOESCHE, W. J. Clinical and microbiological aspects of chemotherapeutic agents used according to the specific plaque hypothesis. J. Dent. Res., v. 58, n. 12, p. 24042412, 1979.

LOESCHE, W. J.; SYED, S. A.; SCHMIDT, E.; MORRISON, E. C. Bacterial profiles of subgingival plaque in periodontitis. J. Periodontol., v. 56, p. 447-456, 1985.

LOPEZ, N. J.; SMITH, P. C.; GUTIERREZ, J. Periodontal therapy may reduce the risk of preterm low birth weight in women with periodontal disease: a randomized controlled trial. J. Periodontol., v. 73, n. 8, p. 911-924, 2002.

MALLAPRAGADA, S. K.; PEPPAS, N. A.; COLOMBO, P. Crystal dissolution-controlled release systems II. Metronidazole release from semicrystalline poly (vinyl alcohol) systems. J. Biomed. Mater. Res., v. 36, n. 1, p. 125-130, 1997.
MANARA, L. R. B.; GROMATZKY, A.; CONDE, M. C.; BRETZ, W. A. Utilização da própolis em odontologia. Rev. FOB, v. 7, n 3/4, p. 15-20, 1999.

MARTIN, L.; WILSON, C. G.; KOOSHA, F.; UCHEGBU, I. F. Sustained buccal delivery of the hydrophobic drug denbufylline using physically cross-linked palmitoyl glycol chitosan hydrogels. Eur. J. Pharm. Biopharm., v. 55, p. 35-45, 2003.

MATSUDA, S.; IWATA, H.; SE, N.; IKADA, Y. Bioadhesion of gelatin films crosslinked with glutaraldehyde. J. Biomed. Mater. Res., v. 45, p. 20-27, 1999.

MAZE, G. I.; REINHART, R. A.; PAYNE, J. B.; MAZE, C.; BAKER, R. A.; BOUWSMA, O. J.; DAMANI, N. C.; FITZGERALD, J. H.; HAMLIN, J. C.; GERLACH, R. W. Gingival fluid tetracycline release from bioerodible gels. J. Clin. Periodontol., v. 23, p. 1133-1136, 1996.

MEDLICOTT, N. J.; JONES, D. S.; TUCKER, I. G.; HOLBOROW, D. W. Preliminary release studies of chlorhexidine (base and diacetate) from poly $(\mu-$ caprolactone) films prepared by solvent evaporation. Int. J. Pharm., v. 84, p. 85-89, 1992.

MEDLICOTT, N. J.; RATHBONE, M. J.; TUCKER, I. G.; HOLBOROW, D. W. Delivery systems for the administration of drugs to the periodontal pocket. $A d v$. Drug Deliv. Rev., v. 13, p. 181-203, 1994.

MINABE, M.; SUZUKI, F.; UMEMOTO, T. Intra-pocket antibiotic therapy using resorbable and non-resorbable slow-release devices containing tetracycline. Periodontal Clin. Investig., v. 22, n. 1, p. 14-21, 2000.

MINABE, M.; TAAKEUCHI, K.; TOMOMATSU, E.; HORI, T.; UMEMOTO, T. Clinical effects of local application of collagen film-immobilized tetracycline. $J$. Clin. Periodontol., v. 16, p. 291-294, 1989a.

MINABE, M.; TAMURA, T.; HORI, T.; UMEMOTO, T. Subgingival administration of tetracycline on a collagen film. J. Periodontol., v. 60, p. 552-556, 1989 b.

MINABE, M.; UEMATSU, A.; NISHIJIMA, K.; TOMOMATSU, E.; TAMURA, T.; HORI, T.; UMEMOTO, T.; HINO, T. Application of a local durg delivery system to periodontal therapy: I development of collagen preparations with immobilized tetracycline. $J$. Periodontol., v. 60, n.2, p. 113-117, 1989c. 
MONBELLI, A. Periodontitis as an infectious disease: specific features and their implications. Oral Dis., v. 9, sup. 6, p. 6-10, 2003.

MURRAY, M. C.; WORTHINGTON, H. V.; BLINKHORN, A. A study to investigate the effect of a propoliscontaining mouthrinse on the inhibition of de novo plaque formation. J. Clin. Periodontol., v. 24, n. 11, p. 796-798, 1997.

NAKAGAWA, T.; YAMADA, S.; OOSUKA, Y.; SAITO, A.; HOSAKA, Y.; ISHIKAWA, T.; OKUDA, K. Clinical and microbiological study of local minocycline delivery (Periocline) following scaling and root planning in recurrent periodontal pockets. Bull. Tokyo Med. Dent. Univ., v. 32, n. 2, p. 63-70, 1991.

NEEDLEMAN, I. G. Controlled drug release in periodontics: a review of new therapies. Br. Dent. J., v. 170, n. 11, p. 405-408, 1991.

NEEDLEMAN, I.G.; MARTIN, G.P.; SMALES, F.C. Characterization of bioadhesives for periodental and oral mucosal drug delivery. J. Clin. Periodontol., v. 25, n. 1, p. 74-82, 1998.

NEWMAN, H. N.; YEUNG, F. I. S.; WANYUSOF, W. A. Z. B.; ADDY, M. Slow release metronidazole and a simplified mechanical oral hygiene regimen in the control of chronic periodontitis. J. Clin. Periodontol., v. 11, p. 576-582, 1984.

NEWMAN, M. G. Current concepts of the pathogenesis of periodontal disease - microbiology emphasis. $J$. Periodontol., v. 56, n. 12, p. 734-739, 1995.

NOGUCHI, T.; IZUMIZAWA, K.; FUKUDA, M.; KITAMURA, S.; SUZUKI, Y.; IKURA, H. New method for local drug delivery using resorbable base material in periodontal therapy. Bull. Tokyo Med. Dent. Univ., v. 31, p. 145-153, 1984.

NORKIEWICZ, D. S.; BREAULT L. G.; WONDERLICH, S. T.; MALONE, K. H. The use of chemotherapeutic agents in localized periodontal pockets. Mil. Med., v. 166, n. 11, p. 940-946, 2001.

NORLING, T.; LADING, P.; ENGSTRON, S.; LARSSON, K.; KROG, N.; MISSEN, S. S. Formulation of a drug delivery system based on a mixture of monoglycerides and triglycerides for use in the treatment of periodontal disease. J. Clin. Periodontol., v. 19, p. 687-692, 1992.
NOTTEN, F.; KOEK-VAN OOSTEN, A.; MIKX, F. Capillary agar diffusion assay for measuring metronidazole in human gingival crevice fluid. Antimicrob. Agents Chemother., v. 21, p. 836-837, 1982.

NOYAN, U.; YILMAZ, S.; KURU, B.; KADIR, T.; ACAR, O.; BUGET, E. A clinical and microbiological evaluation of systemic and local metronidazole delivery in adult periodontitis patients. J. Clin. Periodontol., v. 24, n. 3, p. 158-165, 1997.

OKUDA, K.; WOLFF, L.; OLIVER, R.; OSBORN, J.; STOLTENBERG, J.; BEREUTER, J.; ANDERSON, L.; FOSTER, P.; HARDIE, N.; AEPPLI, D.; HARA, K. Mynocline slow-release formulation effect on subgingival bacteria. J. Periodontol., v. 63, n. 2, p. 73-79, 1992.

OTANI, Y.; TABATA, Y.; IKADA, Y. Effect of additives on gelation and tissue adhesion of gelatin-poly (L-glutamic acid) mixture. Biomaterials, v. 19, p. 2167-2173, 1998.

PAAVOLA, A.; YLIRUUSI, J.; ROSENBERG, P. Controlled release and dura mater permeability of lidocaine and ibuprofen from injectable poloxamer-based gels. $J$. Control. Rel., v. 52, p. 169-478, 1998.

PARK, Y. K.; KOO, M. H.; ABREU, J.A. S.; IKEGAKI, M.; CURY, J. A.; ROSALEN, P. L. Antimicrobial activity of propolis on oral microorganisms. Curr. Microbiol., v. 36, p. 24-28, 1998.

PAVIA, M.; NOBILE, C. G.; ANGELILLO, I. F. metaanalysis of local tetracycline in treating chronic periodontitis. J. Periodontol., v. 74, n. 6, p. 916-932, 2003.

PAVIA, M.; NOBILE, C. G.; BIANCO, A.; ANGELILLO, I. F. Meta-analysis of local metronidazole in the treatment of chronic periodontitis. J. Periodontol., v. 45, n. 6 , p. $830-838,2004$.

PEDRAZZOLI, V.; KILIAN, M.; KARRING, T. Comparative clinical and microbiological affects of topical subgingival application of metronidazole $25 \%$ dental gel and scaling in the treatment of adult periodontitis. J. Clin. Periodontol., v. 19, p. $715-722,1992$.

PEH, K. K.; WONG, C. F. Polymerics films as vehicle for buccal delivery: swelling, mechanical, and bioadhesive properties. J. Pharm. Pharmaceut. Sci., v. 2, n. 2, p. 53$61,1999$. 
PERIOLI, L.; AMBROGI, V.; RUBINI, D.; GIOVAGNOLI, S.; RICCI, M.; BLASI, P.; ROSSI, C. Novel mucoadhesive buccal formulation containing metronidazole for the treatment of periodontal disease. $J$. Control. Rel., v. 95, p. 521-533, 2004.

PITCHER, G. R.; NEWMAN, H. N.; STRAHAN, J. D. Access to subgengival plaque by disclosing agents using mouthrinsing and direct irrigation. J. Clin. Periodontol., v. 7, p. 300-308, 1980.

QUAGLIA, F.; VIGNOLA, M. C.; DE ROSA, G.; LA ROTONDA, M. I.; MAGLIO, G.; PALUMBO, R. New segmented copolymers containing poly( $\mu$-caprolactone) and etheramide segments for the controlled release of bioactive compounds. J. Control. Rel., v. 83, p. 263-271, 2002.

QUEE, T. C. The role of systemic antibiotics in periodontal therapy. J. Can. Dent. Assoc., v. 55, n. 12, p. 967-969, 1989.

RAMFJORD, S. P. maintenance care for treated periodontitis patients. J. Clin. Periodontol., v. 14, p. 433-437, 1987.

RANADIVE, K. S.; BHAT, K. M. Local antimicrobial delivery in periodontal therapy. Indian J. Dent. Res., v. 9 , n. 4, p. 124-130, 1998.

RETHMAN, J.; RETHMAN, M.; SUZUKI, J. Controlled release periodontal chemotherapy: the evolution of antimicrobial delivery systems. Pract. Periodontics Aesthet. Dent., p. 1-8, supplement, 1995.

RODRIGUES, R. M. J.; GONÇALVES, C.; SOUTO, R.; FERES-FILHO, E. J.; UZEDA, M.; COLOMBO, A. P. $\mathrm{V}$. Antibiotic resistance profile of the subgingival microbiota following systemic or local tetracycline therapy. J. Clin. Periodontol., v. 31, p. 420-427, 2004.

ROSKOS, K. V.; FRITZINGER, B. K.; RAO, S. S.; ARMITAGE, G. C.; HELLER, J. Development of a drug delivery system for the treatment of periodontal disease based on bioerodible poly (ortho esters). Biomaterials, v. 16, n. 4, p. 313-317, 1995.

SAGLIE, R.; NEWMAN, M. G.; CARRANZA JR, F. A.; PATTISON, G. L. Bacterial invasion of gingiva in advanced periodontitis in humans. J. Periodontol., v. 53, n. 4, p. 217-222, 1982.
SAKELLARI, D.; VOUROS, I.; KONSTANTINIDIS, A. The use of tetracycline fibres in the treatment of generalised aggressive periodontitis: clinical and microbiological findings. J. Int. Acad. periodontol., v. 5, n. 2, p. 52-60, 2003.

SANTOS, F. A.; BASTOS, E. M. A. F.; UZEDÂ, M.; CARVALHO, M. A. R.; FARIAS, L. M.; MOREIRA, E. S. A. Antibacterial activity of propolis produced in Brazil against Actinobacillus actinomycetemcomitans, Fusobacterium spp. and bacteria from Bacteroides fragilis group isolated from human and marmoset hosts. Anaerobe, v. 5, p. 479-481, 1999.

SASTRAVAHA, G.; YOTNUENGNIT, P.; BOONCONG, P.; SANGTHERAPITIKUL, P. Adjunctive periodontal treatment with Centella asiatica and Punica granatum extracts. A preliminary study. J. Int. Acad. periodontol., v. 5, n. 4 , p. 106-115, 2003.

SCHERLUND, M.; MALMSTEN, M.; HOLMQVIST, P.; BRODIN, A. Thermoseting microemulsions and mixed micellar solutions as drug delivery systems for periodontal anesthesia. Int. J. Pharm., v. 194, p. 103-116, 2000.

SCHWACH-ABDELLAOUI, K.; LOUP, P. J.; VIVIENCASTIONI, N.; MONBELLI, A.; BAEHNI, P.; BARR, J.; HELLER, J.; GURNY, R. Bioerodible injectable poly(ortho ester) for tetracycline controlled delivery to periodontal pockets: preliminary trial in humans. AAPS Pharm. Sci., v. 4, n. 4, p. 1-7, 2002.

SEYMOUR, R. A.; HEASMAN, P. A. Drugs, diseases, and the periodontum. New York: Oxford Medical Publications, Oxford University Press, 1992. 206p.

SLOTS, J. Selective medium of idolation of Actinobacillus actinomycetemcomitans. J. Clin. Microbiol., v. 15, n. 4, p. 606-609, 1982.

SLOTS, J. Subgingival microflora and periodontal disease. J. Clin. Periodontol., v. 6, p. 351-382, 1979.

SLOTS, J. The predominant cultivable organisms in juvenile periodontitis. Scand. J. Dent. Res., v. 84, n. 1, 1976.

SOSKOLONE, W. A.; CHAJEK, T.; FLASHNER, M.; LANDAU, I.; STABHOLTZ, A.; KOLATCH, B.; LERNER, E. I. An in vivo study of the chlorhexidine release profile of the PerioChipTM in the gingival crevicular fluid, plasma and urine. J. Clin. Periodontol., v. 25, p. 1017-1021, 1998. 
SOSKOLONE, W. A.; FREIDMAN, M. F. Intra-periodontal pocket drug delivery systems. In: RATHBONE, M. J. (Ed.). Oral mucosal drug delivery. New York: Marcel Dekker, 1996. v. 74, p. 359-379.

STABHOLZ A, NICHOLAS, A. A, ZIMMERMAN, G. J.; WIKESJO, U. M. Clinical and antimicrobial effects of a single episode of subgingival irrigation with tetracycline $\mathrm{HCl}$ or chlorhexidine in deep periodontal pockets. J. Clin. Periodontol., v. 25, n. 10, p. 794-800, 1998.

STABHOLZ, A.; SELA, M. N.; FRIEDMAN, M.; GOLOMB, G.; SOSKOLONE, W. A. Clinical and microbiological effects of sustained release chlorhexidine in periodontal pockets. J. Clin. Periodontol., v. 13, n. 8, p. 783-788, 1986.

STABHOLZ, A.; SOSKOLONE, W. A.; FRIEDMAN, M.; SELA, M. N. The use of sustained release delivery of chlorhexidine for the maintenance of periodontal pockets: 2-year clinical trial. J. Periodontol., v. 62, n. 7, p. 429-433, 1991.

STEINBERG, D.; FRIEDMAN, M.; SOSKOLNE, A.; SELA, M. N. Anew degradable controlled release device for treatment of periodontal disease: in vitro release study. J. Periodontol., v. 61, n. 7, p. 393-398, 1990.

STEINBERG, D.; FRIEDMAN, M. Sustained release drug delivery devices for local treatment of dental diseases. In: TYLE, P. (ed.). Drug Delivery Devices. New York: Marcel Dekker, 1988. p. 491-515.

STELZEL, M.; FLORES-DE-JACOBY. Topical metronidazole application in recall patients. J. Clin. Periodontol., v. 24, p. 914-919, 1997.

STOLTZE, K. Concentration of metronidazole in periodontal pockets after application of a metronidazole $25 \%$ dental gel. J. Clin. Periodontol., v. 19, p. 698-701, 1992.

STOLTZE, K.; STELLFED, M. Systemic absorption of metronidazole after application of a metronidazole $25 \%$ dental gel. J. Clin. Periodontol., v. 19, p. 693, 1992.

TANNER, A. C. R.; HAFFER, C.; BRATTHAIL, G. T.; VISCONTI, R. A.; SOCRANSKY, S. S. A study of bacteria associated with advancing periodontitis in man. J. Clin. Microbiol., v. 6, p. 278-307, 1979.
THOMSON, S. J.; GRAHAM, G. S.; FANCHER, J. P.; BROOME, J. C.; CAUDIL, R. F. Periodontal effects of local tetracycline delivery by two biodegradable vehicles. J. Dent. Res. v. 71, p. 295, 1992.

TINOCO, E. M. B.; BELDI, M. I.; CAMPEDELLI, F.; LANA, M.; LOUREIRO, C. A.; BELLINI, H. T.; RAMS, T. E.; TINOCO, P. G.; PREUS, H. R.; Clinical and microbiological effects of adjunctive antibiotics in treatment of localized juvekine periodontitis. A controlled clinical trial. J. Periodontol., v. 69, n. 12, p. 1355-1363, 1998.

TONETTI, M.; CUGINI, M. A.; GOODSON, J. M. Zeroorder delivery with periodontal placement of tetracycline-loaded ethylene vinyl acetate fibres. $J$. Periodont. Res., v. 25, p. 243-249, 1990.

TURNBULL, R. S. Chemotherapeutic control of plaque and gingivitis. J. Can. Dent. Assoc., v. 55, n. 12, p. 965-966, 1989.

VAN DER OUDERAA, F. J. G. Anti-plaque agents. Rationale and prospects for prevention of gingivitis and periodontal disease. J. Clin. Periodontol., v. 18, p. 447454, 1991.

VAN STEENBERGHE, D.; BERCY, P.; KOHL, J.; DE BOEVER, J.; ADRIAENS, P.; VANDERFAEILLIE, A.; ANDRIAENSSEN, C.; ROMPEN, E.; DE VREE, H.; MCCARTHY, F.; VANDENHOVEN, G. Subgingival minocycline hydrochloride ointment in moderate to severe chronic adult type periodontitis: a randomized, double blind, vehicle-controlled, multicenter study. $J$. Periodont., v. 64, p. 637, 1993.

VANDERKERCKHOVE, B. N. A.; QUIRYNEN, M.; STEENBERGHE, D. The use of locally-delivered minocycline in the treatment of chronic periodontitis. A review of the literature. J. Clin. Periodontol., v. 25, p. 964-968, 1998.

VARSHOSAZ, J.; DEHGHAN, Z. Development and characterization of buccoadhesive nifedipine tablets. Eur. J. Pharm. Biopharm., v. 54, p. 135-141, 2002.

VINHOLIS,A.H. C;;FIGUEIREDO, L. C.; MARCANTONIO JUNIOR, E.; MARCANTONIO, R. A. C.; SALVADOR, S. L. S.; GOISSIS, G. Subgingival utilization of a $1 \%$ chlorhexidine collagen gel for the treatment of periodontal pockets. A clinical and microbiological study. Braz. Dent. J., v. 12, n. 3, p. 209-213, 2001. 
VYAS, S. P.; SIHORKAR, V.; DUBEY, P. K. Preparation, characterization and in vivo antimicrobial activity of metronidazole bearing lectinized liposomes for intraperiodontal pocket delivery. Pharmazie, v. 56, n. 7, p. 554-560, 2001.

WAN YUOSOF, W. Z. A.; NEWMAN, H. N.; STRAHAN, J. D.; COVENTRY, J. F. Subgingival metronidazole in dyalisis tubing and subgingival chlorhexidine irrigation in the control of chronic inflammatory periodontal disease. J. Clin. Periodontol. v. 11, n. 166-175, 1984.

WILLIAMS, R. C.; HOWELL, T. H. New technologies for the diagnosis of periodontal disease. J. Prothet. Detn., v. 69, n.6, p. 551-557, 1993.
WONG, C. F.; YUEN, K. H.; PEH, K. K. Formulation and evaluation of controlled release Eudragit buccal patches. Int. J. Pharm., v. 178, p. 11-22, 1999.

YEUNG, F. I. S.; NEWMAN, H. N.; ADDY, M. Subgingival metronidazole in acrilic resin vs chlorhexidine irrigation in the control of chronic periodontitis. J. Periodontol., v. 54, n. 11 , p. $651-657,1983$.

Recebido para publicação em 20 de dezembro de 2004. Aceito para publicação em 08 de fevereiro de 2006. 
